\title{
Plasma vitamin C: what does it measure?
}

\author{
AR Ness ${ }^{1, *}$, KT Khaw $^{2}$, S Bingham ${ }^{3}$ and NE Day ${ }^{4}$ \\ 'Senior Lecturer in Epidemiology, University of Bristol, Department of Social Medicine, Canynge Hall, \\ Whiteladies Road, Bristol BS8 2PR, UK: ${ }^{2}$ Professor of Clinical Gerontology, Department of Clinical Gerontology, \\ Addenbrooke's Hospital, Hills Road, Cambridge CB2 2QQ, UK: ${ }^{3}$ Senior Scientist, MRC Dunn Clinical Nutrition \\ Centre, Hills Road, Cambridge CB2 2DH, UK: ${ }^{4}$ Professor of Public Health, Institute of Public Health, University \\ Forvie Site, Robinson Way, Cambridge CB2 2SR, UK
}

Submitted 28 July 1998: Accepted 23 September 1998

\begin{abstract}
Objective: To examine the association between self-reported consumption of foods and plasma vitamin C levels.

Design: A cross-sectional analysis of dietary data and plasma vitamin C levels. Subjects placed the following foods into frequency categories: fresh fruit, leafy greens, other vegetables, fatty fish, other fish, chicken, meat, meat products, eggs, cheese and brown bread. The six frequency categories ranged from 'never' to 'at least daily'. Plasma vitamin C was measured by fluorometric assay.

Setting: A population-based cohort study in Norfolk, UK.

Subjects: 598 men and 566 women aged 45-74 years not taking vitamin supplements. Results: Plasma vitamin C was positively correlated with intake of fresh fruit $(r=0.29$ in men and $r=0.25$ in women, $P<0.001)$, leafy greens $(r=0.20$ in men $P<0.001, r=$ 0.13 in women $P<0.01)$, other vegetables $(r=0.20$ in men $P<0.001, r=0.14$ in women $P<0.01)$ and brown bread $(r=0.28$ in men, $r=0.17$ in women, $P<0.001)$ and negatively associated with intake of meat products $(r=-0.13$ in men $P=0.02, r=-0.10$ in women $P<0.01)$. The difference in plasma vitamin $\mathrm{C}$ between never and daily eaters of brown bread was $13.6 \mu \mathrm{mol} \mathrm{l}^{-1}$ in men and $9.9 \mu \mathrm{mol}^{-1}$ in women, $P<0.001$.

Conclusions: These data suggest that plasma vitamin $\mathrm{C}$ is not only a marker of foods rich in vitamin $\mathrm{C}$ but of certain patterns of food consumption. Such patterns are likely to be population specific and might explain inconsistencies in biomarker-disease associations.
\end{abstract}

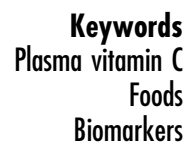

The difficulties in measuring diet accurately in freeliving individuals has stimulated the search for biomarkers of food intake for use in epidemiological studies of nutrition and chronic disease ${ }^{1}$. The associations of these biological measures with disease are often reported without reference to either the major food sources of the constituent measured or the food correlates of the biological measure.

Plasma vitamin C correlates well with previous 7 days intake of vitamin $\mathrm{C}^{2}$ and though affected by other factors such as age, sex and smoking habit is considered a good marker of intake for those consuming between 30 and $90 \mathrm{mg} \mathrm{day}^{-1}$. The main food sources of vitamin $\mathrm{C}$ in the British diet were: vegetables (46\%), beverages (22\%) which include fruit juices, and fruit and nuts $(17 \%)^{3}$.

We examined the association between plasma vitamin C and various food groups in just under 2000 subjects recruited to a prospective study of diet and health ${ }^{4}$.

\section{Method}

All men and women aged 45-74 years, identified from the lists of general practices in Norfolk, East Anglia, were invited to join the study. Informed consent was obtained from participants. They completed a health and lifestyle questionnaire which included questions on smoking history and asked whether they took regular vitamin supplements.

As part of the questionnaire participants were also asked to judge how often they consumed 11 food groups. These food groups were: fresh fruit (e.g. apples, oranges, pears), green leafy vegetables (e.g. cabbage, broccoli), other vegetables (e.g. peas, carrots, beans, tomatoes), fatty fish (e.g. herring, sprats, pilchards, mackerel), other fish (e.g. cod, tuna, haddock), chicken, meat (e.g. chops, roasts, stews), meat products (e.g. sausages, ham, beefburgers), eggs, cheese and wholemeal/brown bread. Frequency options were: never, seldom, once a week, 2-4 times 
a week, 5-6 times a week or once or more daily. Detailed guidance was not given on either the nature of these food groups or on what constituted a portion. These options were converted into portions per month as follows: 0, 1, 4, 12, 22 and 28.

Subjects were invited to attend their general practitioner's surgery for a health check where their height and weight were measured and blood was taken. Subjects were not fasted. The height and weight were measured with subjects in light clothing and with their shoes removed. Height was measured to the nearest $0.1 \mathrm{~cm}$ using a stadiometer and weight was measured to the nearest $100 \mathrm{~g}$ using Salter scales (model 975). The body mass index, weight $(\mathrm{kg}) /$ /height $(\mathrm{m})]^{2}$, was used as the measure of ponderosity.

Vitamin C was measured using plasma prepared from blood drawn using monovettes into vacuum tubes containing citrate. The blood was stored overnight in dark sealed boxes in a refrigerator at $4-7{ }^{\circ} \mathrm{C}$, then spun at $2100 \boldsymbol{g}$ for $15 \mathrm{~min}$ at $4^{\circ} \mathrm{C}$. Plasma was stabilized in a standardized volume of metaphosphoric acid and then stored at $-70^{\circ} \mathrm{C}$. Stability studies have indicated that though vitamin C levels fall after overnight storage they are closely associated with initial values - the Spearman rank correlation coefficient ${ }^{5}$ was 0.84 . Plasma vitamin C was estimated using a fluorometric assay ${ }^{6}$ within 1 week of sampling. The coefficient of variation at the lower end of the range was $6.2\left(\right.$ mean $=7.5 \mu \mathrm{moll}^{-1}$ and $n=10)$ and was 2.7 at the upper end of the range (mean $=86 \mu \mathrm{mol} \mathrm{l}^{-1}$ and $n=10$ ).

The calculated frequency categories were used in the analyses. Pearson correlation coefficients and adjusted means were calculated by analysis of variance (ANOVA) using SPSS for Windows 6.0 $0^{7}$. Age was used as a continuous variable, rather than as a categorical variable, to calculate age-adjusted values. All hypothesis tests were two tailed.

\section{Results}

Data were available on plasma vitamin $\mathrm{C}$ concentration in 835 men and 1025 women recruited to the study between 1993 and 1994. Regular supplement takers were excluded leaving 598 men and 566 women for the analysis. The age-adjusted correlations between plasma vitamin $\mathrm{C}$ and food groups were calculated. The ageadjusted correlations were calculated again after excluding the 75 men and 70 women who were current smokers. These associations are shown in Table 1 . The age-adjusted mean plasma vitamin $\mathrm{C}$ values for frequencies of food consumption were calculated in the five food groups where a statistically significant correlation was observed in both men and women. The mean values of plasma vitamin $\mathrm{C}$ for different frequencies of food consumption are shown in Table 2 . The results were essentially the same when

Table 1 Correlation of reported frequency of consumption of various food groups (in times per month, 0-28) with plasma vitamin C status in 598 men and 566 women aged 45-74 years in Norfolk 1993-94

\begin{tabular}{lcc}
\hline Food item & $\begin{array}{c}\text { Age-adjusted correlation } \\
\text { with plasma vitamin C }\end{array}$ & $\begin{array}{c}\text { Age-adjusted correlation } \\
\text { with plasma vitamin C } \\
\text { excluding current smokers }\end{array}$ \\
\hline Men (number) & 598 & 523 \\
Fresh fruit & $0.29^{* * *}$ & $0.27^{* * *}$ \\
Green leafy vegetables & $0.21^{* * *}$ & $0.22^{* * *}$ \\
Other vegetables & $0.20^{* * *}$ & $0.18^{* * *}$ \\
Fatty fish & $0.06^{*}$ & 0.09 \\
Other fish & 0.04 & 0.06 \\
Chicken & 0.02 & 0.02 \\
Meat & $-0.09^{*}$ & $-0.11^{*}$ \\
Meat products & $-0.11^{* *}$ & $-0.14^{* *}$ \\
Eggs & $-0.01^{*}$ & -0.02 \\
Cheese & $0.11^{* *}$ & $0.10^{*}$ \\
Wholemeal/brown bread & $0.28^{* *}$ & $0.26^{* * *}$ \\
Women (number) & 566 & 496 \\
Fresh fruit & $0.26^{* * *}$ & $0.21^{* * *}$ \\
Green leafy vegetables & $0.12^{*}$ & 0.10 \\
Other vegetables & $0.13^{* *}$ & 0.07 \\
Fatty fish & $0.08^{*}$ & 0.07 \\
Other fish & 0.02 & 0.02 \\
Chicken & 0.02 & 0.01 \\
Meat & $0.05^{* *}$ & 0.06 \\
Meat products & $-0.14^{* *}$ & -0.09 \\
Eggs & -0.05 & -0.05 \\
Cheese & $-0.03^{* * *}$ & -0.07 \\
Wholemeal/brown bread & $0.18^{* *}$ & $0.12^{*}$ \\
\hline P & &
\end{tabular}

${ }^{*} P<0.05,{ }^{* *} P<0.01,{ }^{* *} P<0.001$. 
Table 2 Age-adjusted mean plasma vitamin $\mathrm{C}$ levels in $\mu \mathrm{mol} \mathrm{I}^{-1}$ by frequency of food consumption (number in parentheses) in 598 men and 566 women aged 45-74 years in Norfolk 1993-94

\begin{tabular}{|c|c|c|c|c|c|c|c|}
\hline & Never & Seldom & Weekly & $\begin{array}{l}\text { 2-4 times } \\
\text { week }^{-1}\end{array}$ & $\begin{array}{l}5 \text { times } \\
\text { week }^{-1}\end{array}$ & Daily & $\begin{array}{c}\text { ANOVA } \\
(P \text { value })\end{array}$ \\
\hline \multicolumn{8}{|l|}{ Men } \\
\hline Fresh fruit & $37.6(8)$ & $35.2(59)$ & $39.8(58)$ & $41.7(165)$ & $46.8(87)$ & $50.4(215)$ & $<0.0001$ \\
\hline Green leafy vegetables & $31.9(5)$ & $40.4(30)$ & $42.6(53)$ & $42.9(274)$ & $46.2(121)$ & $52.4(106)$ & $<0.0001$ \\
\hline Other vegetables & $18.5(2)$ & $44.6(5)$ & $33.3(14)$ & $41.2(245)$ & $45.4(185)$ & $49.2(139)$ & $<0.0001$ \\
\hline Wholemeal/brown bread & $37.4(76)$ & $41.5(132)$ & $43.2(38)$ & $40.9(93)$ & $49.7(59)$ & $51.0(191)$ & $<0.0001$ \\
\hline Meat products & $52.3(22)$ & $47.9(118)$ & $43.6(239)$ & $42.9(176)$ & $41.7(14)$ & $44.7(5)$ & $<0.05$ \\
\hline \multicolumn{8}{|l|}{ Women } \\
\hline Fresh fruit & $49.4(3)$ & $46.6(31)$ & $49.4(38)$ & $49.6(115)$ & $52.5(74)$ & $58.3(292)$ & $<0.0001$ \\
\hline Green leafy vegetables & $31.3(2)$ & $47.1(20)$ & $53.5(47)$ & $53.6(246)$ & $54.1(99)$ & $58.3(146)$ & $<0.05$ \\
\hline Other vegetables & $34.6(2)$ & $46.2(2)$ & $52.2(9)$ & $52.1(214)$ & $54.7(172)$ & $58.0(156)$ & $<0.05$ \\
\hline Wholemeal/brown bread & $47.8(31)$ & $48.3(77)$ & $51.7(38)$ & $56.9(109)$ & $51.8(57)$ & $57.7(222)$ & $<0.0001$ \\
\hline Meat products & $59.2(33)$ & $55.6(161)$ & $54.4(254)$ & $50.0(78)$ & $66.4(2)$ & $51.1(2)$ & 0.11 \\
\hline
\end{tabular}

the analyses were repeated adjusting for body mass index (data not shown). As the results were materially unaffected by exclusion of current smokers they were included in the subsequent analyses presented in Tables 3 and 4 .

To explore the association between the reported frequency of consumption of these five food groups and plasma vitamin $\mathrm{C}$ further, the age-adjusted correlations between food groups were calculated. These correlations are shown in Table 3 . The ageadjusted correlations of plasma vitamin $\mathrm{C}$ and frequency of consumption of these five food groups were then calculated after adjustment for each of the foods one at a time and after adjustment for the other four foods simultaneously. These correlations are shown for men and women in Table 4.

\section{Discussion}

In this British population we found that plasma vitamin $\mathrm{C}$ was consistently correlated with reported frequency of intake of foods rich in vitamin $\mathrm{C}$ (fruit and vegetables) and also with other foods (brown or wholemeal bread). The differences in plasma vitamin
C between the top and bottom categories of brown bread consumption were of the same magnitude as for fruit even though brown bread contains no vitamin $\mathrm{C}^{8}$. As far as we are aware, this is the first study to examine the association between plasma vitamin $\mathrm{C}$ level intake and food intake, though previous studies have looked at the association between plasma vitamin $\mathrm{C}$ and nutrient intake $\mathrm{e}^{9,10}$.

Though plasma vitamin C level provides a good measure of recent vitamin $\mathrm{C}$ intake it is affected by other factors such as age, sex and smoking ${ }^{2}$. The association with brown bread was present after regular supplement takers were excluded and persisted after controlling for age and body mass index and after stratifying by sex and current smoking. The association between brown bread consumption and plasma vitamin $\mathrm{C}$, though attenuated after adjustment for frequency of consumption of other food groups, remained and was still statistically significant. The questions on the frequency of food intake used in this analysis did not give detailed guidance on foods or portion sizes. For example, participants were not told whether to include fruit juice or canned fruit as fruit. Frequency of consumption of some foods may thus be

Table 3 Age-adjusted correlations between reported frequency of consumption (in times per month, 0-28) of five foods (associated with plasma vitamin C levels) in 598 men and 566 women aged 45-74 years in Norfolk, 1993-94

\begin{tabular}{|c|c|c|c|c|c|}
\hline & Fresh fruit & Green vegetables & Other vegetables & Meat products & Brown bread \\
\hline \multicolumn{6}{|l|}{ Men } \\
\hline Fresh fruit & - & 0.26 *** & $0.32 * * *$ & -0.02 & $0.29 * * *$ \\
\hline Green vegetables & - & - & $0.57^{* * *}$ & -0.06 & $0.22 * * \star$ \\
\hline Other vegetables & - & - & - & 0.03 & 0.23 *** \\
\hline Meat products & - & - & - & - & -0.03 \\
\hline Brown bread & - & - & - & - & - \\
\hline \multicolumn{6}{|l|}{ Women } \\
\hline Fresh fruit & - & $0.28^{* * *}$ & $0.29 * * *$ & -0.06 & $0.24^{* * *}$ \\
\hline Green vegetables & - & - & $0.54^{* * *}$ & -0.06 & $0.17^{* * *}$ \\
\hline Other vegetables & - & - & - & -0.00 & $0.20^{* * *}$ \\
\hline Meat products & - & - & - & - & -0.12 * \\
\hline Brown bread & - & - & - & - & - \\
\hline
\end{tabular}

${ }^{*} P<0.05,{ }^{* *} P<0.01,{ }^{* * *} P<0.001$. 
Table 4 Adjusted correlation of reported frequency of consumption of various food groups (in times per month, 0-28) with plasma vitamin C status in 598 men and 566 women aged 45-74 years in Norfolk 1993-94

\begin{tabular}{|c|c|c|c|c|c|c|c|}
\hline Food item & Age & $\begin{array}{l}\text { Age and } \\
\text { fresh fruit }\end{array}$ & $\begin{array}{l}\text { Age and } \\
\text { leafy veg }\end{array}$ & $\begin{array}{l}\text { Age and } \\
\text { other veg }\end{array}$ & $\begin{array}{l}\text { Age and } \\
\text { meat prod. }\end{array}$ & $\begin{array}{c}\text { Age and } \\
\text { brown bread }\end{array}$ & $\begin{array}{l}\text { Age and four } \\
\text { other foods }\end{array}$ \\
\hline \multicolumn{8}{|l|}{ Men } \\
\hline Fresh fruit & $0.29 * \star \star$ & - & $0.24^{* * *}$ & $0.24^{* * *}$ & $0.29 * * *$ & $0.22^{\star \star \star}$ & $0.19 * * *$ \\
\hline Leafy vegetables & $0.21^{* * *}$ & $0.15^{* *}$ & - & 0.12 * & 0.21 * & $0.16^{* * *}$ & 0.07 \\
\hline Other vegetables & $0.20^{* * *}$ & 0.12 ** & 0.10 * & - & $0.21^{\star \star *}$ & $0.15^{* *}$ & 0.05 \\
\hline Meat products & $-0.11^{* *}$ & $-0.11 *$ & $-0.10 *$ & $-0.12 *$ & - & -0.10 * & $-0.10^{*}$ \\
\hline Brown bread & $0.28^{* * *}$ & $0.21^{* * *}$ & $0.24^{* * *}$ & 0.24 *** & $0.28^{* * *}$ & - & $0.19^{* * *}$ \\
\hline \multicolumn{8}{|l|}{ Women } \\
\hline Fresh fruit & $0.26 * * *$ & - & $0.24^{* * *}$ & $0.24^{* * *}$ & $0.26^{* * *}$ & $0.23^{* * *}$ & $0.20^{* * *}$ \\
\hline Leafy vegetables & 0.12 * & 0.05 & - & 0.06 & 0.11 * & 0.09 & 0.01 \\
\hline Other vegetables & $0.13^{* *}$ & 0.06 & 0.08 & - & $0.13^{* *}$ & 0.10 * & 0.03 \\
\hline Meat products & $-0.14^{* *}$ & $-0.13^{* *}$ & $-0.13^{* *}$ & $-0.14^{* *}$ & - & -0.12 * & $-0.12^{*}$ \\
\hline Brown bread & $0.18^{* * *}$ & 0.12 * & $0.16^{* *}$ & $0.15^{* *}$ & $0.16^{* * *}$ & - & 0.10 * \\
\hline
\end{tabular}

${ }^{*} P<0.05,{ }^{* *} P<0.01,{ }^{\star \star *} P<0.001$.

recorded more accurately than for others. It may be that data from better dietary measurement instruments, such as food diaries which will be available on these subjects in due course $^{11}$, will be better able to disentangle these issues of confounding.

It is possible that people who eat diets rich in vitamin $\mathrm{C}$ over-report consumption of brown bread. It is also possible that a constituent or constituents contained in brown bread increase plasma vitamin C levels independently of vitamin $\mathrm{C}$ intake. Both of these explanations seem unlikely.

Our results suggest that plasma vitamin C level is an indicator of certain patterns of food consumption. Equally particular patterns of food consumption may be indicators of plasma vitamin C status. These food pattern-nutritional biomarker associations are likely to be population specific. Such differences might explain inconsistencies between studies in the observed associations between biomarkers and disease and between food pattern and disease. To aid interpretation of their findings investigators of epidemiological studies of nutritional biomarkers and disease should also report data on the associations between foods and disease.

\section{Acknowledgements}

The cohort of the European prospective investigation into cancer in Norfolk is funded by: the Cancer Research Campaign; the British Heart Foundation; the Department of Health; the Europe against Cancer Programme Commission of the European Communities; the Medical Research Council; the Ministry of Agriculture, Fisheries and Food; and the World Health Organization.

We thank the staff of EPIC for their invaluable contributions to the study. We are indebted to the general practitioners who allowed us to approach people on their lists and to the people of Norfolk who took part in this study.

Dr Ness was, until recently, supported by a Wellcome Research Training Fellowship in Clinical Epidemiology.

\section{References}

1 Pearce N, de Sanjose S, Boffetta P, Kogevinas M, Saracci R, Savitz D. Limitations of biomarkers of exposure in cancer epidemiology. Epidemiology 1995; 6: 190-4.

2 Bates CJ, Thurnham DI. Biochemical markers of nutrient intake. In: Margetts BM, Nelson M, eds. Design Concepts in Nutritional Epidemiology. Oxford: Oxford University Press, 1991: 192-265.

3 Gregory J, Foster K, Tyler H, Wiseman M. The Dietary and Nutritional Survey of British Adults. London: HMSO, 1990.

4 Riboli E. Nutrition and cancer: background and rationale of the European prospective Investigation into Cancer and Nutrition (EPIC). Ann. Oncol. 1992; 3: 783-91.

5 Key TJA, Oakes S, Davey G, Moore J, Edmond LM, McLoone UJ, Thurnham DI. Stability of vitamins A, C, E, carotenoids, lipids, and testosterone in whole blood stored at $4 \mathrm{C}$ for 6 and 24 hours before separation of serum and plasma. Cancer Epidemiol. Biomarkers Prevention 1996; 5: 811-14.

6 Vuilleumier JP, Keck E. Fluorometric assay of vitamin C in biological materials using a centrifugal analyser with fluorescence attachment. J. Micronutr. Analys. 1989; 5 $25-34$.

7 SPSS Inc. SPSS for Windows, release 6.0. Chicago, USA: 1993.

8 Bolland B, Welch AA, Unwin ID, Buss DH, Paul AA, Southgate DAT. McCance and Widdowson's The Composition of Foods, fifth edition. London: Royal Society of Chemistry, 1991.

9 Jacob RA, Otradovec CL, Russell RM et al. Vitamin C status and nutrient interactions in a healthy elderly population. Am. J. Clin. Nutr. 1988; 48: 1436-42.

10 Heseker $\mathrm{H}$, Schneider R. Requirement and supply of vitamin $\mathrm{C}, \mathrm{E}$ and $\beta$-carotene for elderly men and women. Eur.J. Clin. Nutr. 1994; 48: 118-27.

11 Bingham SE, Gill C, Welch A et al. Validation of dietary assessment in the UK arm of EPIC using weighed records, and 24-hour urinary nitrogen and potassium and serum vitamin C and carotenoids as biomarkers. Int. J. Epidemiol. 1997; 26 (suppl. 1): S137-S151. 